\title{
Curcumin and Coagulopathy in the COVID19 Era
}

\author{
Padmanaban S. Suresh ${ }^{1}$
}

Received: 30 June 2020/Accepted: 8 July 2020/Published online: 15 July 2020

(C) Association of Clinical Biochemists of India 2020

\section{Dear Editor}

I read with great interest the article by Manoharan et al., 2020, proposing Curcumin as supportive therapy for COVID-19 disease published in your journal [1]. I want to highlight further the connection between COVID-19 associated coagulopathies and how proposing curcumin will be beneficial in this context from the available literature knowledge. As of Jun 18, 2020, COVID-19 confirmed cases are 8, 242, 999, and 445, 535 deaths globally (World Health Organization). India reports 1, 63, 248 active cases and 12, 573 deaths due to COVID-19 infections (Ministry of Health and family welfare, Govt of India). COVID-19 patients exhibit thrombotic complications apart from sepsis, pneumonia, respiratory failure, etc., One of the characteristic features of COVID-19 disease is the associated coagulopathy with increased circulating D- dimer concentrations. D -dimer is a fibrin degradation product that is present in blood after blood clot fibrinolysis. It is named because it contains fibrin protein, two D fragments joined by a cross-link. Evaluating D-dimer concentrations assist in predicting the mortality in COVID-19 patients, and patients with Ddimer levels $>1 \mu \mathrm{g} / \mathrm{L}$ on admission were associated with higher mortality [2-4]. There is accumulating evidence of COVID-19 associated coagulopathies as evident by the rising number of research publications in this context. International society of thrombosis and hemostasis proposes an algorithm of measuring D- dimer, prothrombin time, platelet count and fibrinogen in all patients with

Padmanaban S. Suresh

surepadman@gmail.com; surepadman@rediffmail.com

1 School of Biotechnology, National Institute of Technology, Calicut, Kerala 673601, India
COVID-19 infection [5]. Markedly raised D-dimer (maybe 3-4 fold increase) prolonged prothrombin time, platelet count $\left(100 \times 10^{9} / \mathrm{L}\right)$, fibrinogen $(<2 \mathrm{~g} / \mathrm{L})$ are guiding parameters in the management of COVID-19 patients. Two hypotheses can explain the hypercoagulable state and secondary hyperfibrinolysis in vivo leading to coagulopathies during COVID-19 infection. One is the elevated proinflammatory cytokines (IL-6, IL-1, and TNF$\alpha$ ), leading to microvasculature damage and endothelial dysfunction in the lungs, causing hemostasis derangements and pulmonary thrombi. The other alternative hypothesis is the direct or indirect effect of the virus on coagulation pathways causing systemic thrombosis [6]. Antiviral treatments are generally useful and benefit patients; however, treatment strategies that counteract inflammation and coagulopathies may be more promising for COVID-19 patients. Curcumin is a natural compound that exhibits antiviral, antiinflammatory properties, etc. [1], and the research community is continuously making an impressive effort to understand curcumin benefits as an alternative and complementary medicine. Investigators have explored the antithrombotic activities of Curcumin and mitigating effect on thrombosis by modulating platelet numbers, D-dimer and plasminogen activator inhibitor -1 in mice [7-9]. COVID-19 patients show improvement on treatment with low molecular weight heparin that acts as an anticoagulant and antiinflammatory agent and various other anticoagulants are being tried in the management of thrombotic complications. Can Curcumin being a natural product be used as an adjunct to the above treatments? As such therapeutic potential of Curcumin is explored in various clinical trials, the untapped potential of Curcumin as an antithrombotic agent in COVID-19 associated coagulopathies is desirable. 


\section{Compliance with Ethical Standards}

Conflict of interest The authors declare that they have no conflict of interest.

Research Involving Human Participants and or Animals Not applicable.

Informed Consent Not applicable.

\section{References}

1. Manoharan Y, Haridas V, Vasanthakumar KC, Muthu S, Thavoorullah FF, Shetty P. Curcumin: a Wonder Drug as a Preventive Measure for COVID19 Management. Ind J Clin Biochem (2020) Ahead of print.

2. Zhang L, Yan X, Fan Q, Liu H, Liu X, Liu Z, et al. D-dimer levels on admission to predict in-hospital mortality in patients with Covid-19. J Thromb Haemost. 2020;18(6):1324-9.

3. Huang C, Wang Y, Li X, Ren L, Zhao J, Hu Y, et al. Clinical features of patients infected with 2019 novel coronavirus in Wuhan, China. Lancet. 2020;395(10223):497-506.
4. Zhou F, Yu T, Du R, Fan G, Liu Y, Liu Z, et al. Clinical course and risk factors for mortality of adult inpatients with COVID-19 in Wuhan, China: a retrospective cohort study. Lancet. 2020;395:1054-62.

5. Thachil J, Tang N, Gando S, Falanga A, Cattaneo M, Levi M, et al. ISTH interim guidance on recognition and management of coagulopathy in COVID-19. J Thromb Haemostasis. 2020;18(5):1023-6.

6. The Lancet Haematology. COVID-19 coagulopathy: an evolving story. Lancet Haematol. 2020;7(6):e425. https://doi.org/10.1016/ S2352-3026(20)30151-4.

7. Kim DC, Ku SK, Bae JS. Anticoagulant activities of curcumin and its derivative. BMB Rep. 2012;45(4):221-6.

8. Nemmar A, Subramaniyan D, Ali BH. Protective effect of curcumin on pulmonary and cardiovascular effects induced by repeated exposure to diesel exhaust particles in mice. PLoS ONE. 2012;7(6):e39554.

9. Keihanian F, Saeidinia A, Bagheri RK, Johnston TP, Sahebkar A. Curcumin, hemostasis, thrombosis, and coagulation. J Cell Physiol. 2018;233:4497-511.

Publisher's Note Springer Nature remains neutral with regard to jurisdictional claims in published maps and institutional affiliations. 